\title{
One-Year Survival Following Early Revascularization for Cardiogenic Shock
}

\section{Citation}

Hochman, Judith S. 2001. “One-Year Survival Following Early Revascularization for Cardiogenic Shock." JAMA 285 (2) (January 10): 190. doi:10.1001/jama.285.2.190.

\section{Published Version}

doi:10.1001/jama.285.2.190

\section{Permanent link}

http://nrs.harvard.edu/urn-3:HUL.InstRepos:29666956

\section{Terms of Use}

This article was downloaded from Harvard University's DASH repository, and is made available under the terms and conditions applicable to Other Posted Material, as set forth at http:// nrs.harvard.edu/urn-3:HUL.InstRepos:dash.current.terms-of-use\#LAA

\section{Share Your Story}

The Harvard community has made this article openly available.

Please share how this access benefits you. Submit a story.

\section{Accessibility}




\section{One-Year Survival Following Early Revascularization for Cardiogenic Shock}

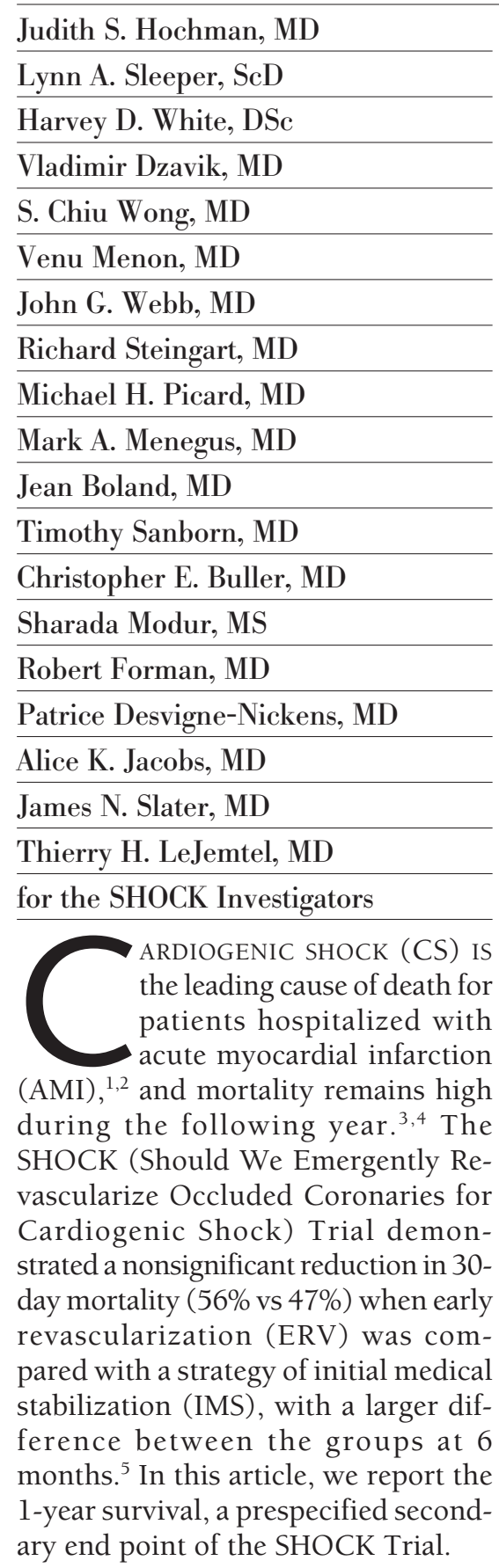

Context Cardiogenic shock (CS) is the leading cause of death for patients hospitalized with acute myocardial infarction (AMI).

Objective To assess the effect of early revascularization (ERV) on 1-year survival for patients with AMI complicated by CS.

Design The SHOCK (Should We Emergently Revascularize Occluded Coronaries for Cardiogenic Shock) Trial, an unblinded, randomized controlled trial from April 1993 through November 1998.

Setting Thirty-six referral centers with angioplasty and cardiac surgery facilities.

Patients Three hundred two patients with AMI and CS due to predominant left ventricular failure who met specified clinical and hemodynamic criteria.

Interventions Patients were randomly assigned to an initial medical stabilization (IMS; $n=150$ ) group, which included thrombolysis (63\% of patients), intra-aortic balloon counterpulsation (86\%), and subsequent revascularization (25\%), or to an ERV group $(n=152)$, which mandated revascularization within 6 hours of randomization and included angioplasty (55\%) and coronary artery bypass graft surgery (38\%).

Main Outcome Measures All-cause mortality and functional status at 1 year, compared between the ERV and IMS groups.

Results One-year survival was $46.7 \%$ for patients in the ERV group compared with $33.6 \%$ in the IMS group (absolute difference in survival, $13.2 \%$; $95 \%$ confidence interval $[\mathrm{Cl}], 2.2 \%-24.1 \% ; P<.03$; relative risk for death, $0.72 ; 95 \% \mathrm{Cl}$, 0.54-0.95). Of the 10 prespecified subgroup analyses, only age ( $<75$ vs $\geq 75$ years) interacted significantly $(P<.03)$ with treatment in that treatment benefit was apparent only for patients younger than 75 years (51.6\% survival in ERV group vs $33.3 \%$ in IMS group). Eighty-three percent of 1 -year survivors (85\% of ERV group and $80 \%$ of IMS group) were in New York Heart Association class I or II.

Conclusions For patients with AMI complicated by CS, ERV resulted in improved 1 -year survival.We recommend rapid transfer of patients with AMI complicated by CS, particularly those younger than 75 years, to medical centers capable of providing early angiography and revascularization procedures.

JAMA. 2001;285:190-192

www.jama.com

\section{METHODS}

The SHOCK Trial design (an unblinded, randomized controlled trial) has been previously reported. ${ }^{6}$ Thirty-six referral centers with angioplasty and cardiac surgery facilities participated from April 1993 through November 1998. Patients with AMI who developed CS due to left ventricular failure at 36 hours or less were eligible if the electrocardiogram results showed ST-segment elevations or $\mathrm{Q}$ waves, posterior infarction, or new left bundle-branch block. Clinical and hemodynamic criteria indicating CS and the absence of all exclusion criteria were required for patient inclusion. ${ }^{5,7} \mathrm{~Pa}$ tients were randomly assigned to undergo ERV, with either percutaneous transluminal coronary angioplasty

Author Affiliations: A complete list of the institutional affiliations for the SHOCK investigators was published previously. N Engl J Med. 1999;341:625-634. Corresponding Author and Reprints: Judith S. Hochman, MD, St Luke's-Roosevelt Hospital Center, 1111 Amsterdam Ave, New York, NY 10025. 
(PTCA) or coronary artery bypass graft (CABG) surgery at 6 hours or less, or to IMS, which included patients undergoing thrombolysis, intra-aortic balloon counterpulsation (IABP) and subsequent revascularization with PTCA or CABG permitted 54 hours or more following randomization. The IABP procedure was performed in $86 \%$ of patients, thrombolysis in $63 \%$ of IMS patients, and subsequent revascularization in $25 \%$ of patients. $^{5}$

Assignment of the New York Heart Association (NYHA) class was determined by a standardized telephone interview 1 year following AMI. Beginning in 1995, rehospitalization data were obtained via telephone.

Dichotomous survival end points were calculated based on survival times from randomization, without regard to heart transplantation. Fisher exact test was used to compare survival rates, and the normal approximation to the binomial was used to estimate the $95 \%$ confidence interval (CI) for the rate difference between groups. The BreslowDay test of homogeneity of odds ratios was used to assess the interaction between treatment group and 10 prespecified subgroup variables., ${ }^{5,7}$ The KaplanMeier product-limit estimator and the log-rank test were used to analyze continuous survival times with censoring at the date of heart transplantation for $4 \mathrm{pa}-$ tients. In addition, 1 IMS patient who was lost to follow-up before 1 year was omitted from the survival analysis because of informative censoring (since this patient was not found in the Social Security Death Index, he/she is likely to be alive). All statistical analyses were conducted in $\mathrm{SAS}^{8}$ and S-Plus. ${ }^{9}$

\section{RESULTS}

The mean (SD) age of enrolled patients was 66 (11) years; $32 \%$ were female, $33 \%$ had history of AMI, 31\% had diabetes mellitus, and $46 \%$ had hypertension. Fifty-five percent of patients were transferred from primary to tertiary care hospitals, by protocol 12 hours or less after CS. ${ }^{5}$ Eight patients (5 ERV and 3 IMS) were determined postrandomization to have aortic dissection, left ventricular free wall rupture, tamponade, or severe mitral regurgitation. Vital status at 1 year was available for 301 of 302 patients.

At 1-year postrandomization, there was a significant difference in survival between the ERV $(n=152)$ and IMS $(\mathrm{n}=149)$ groups $(46.7 \%$ vs $33.6 \%, P$ $<.03$ ) (relative risk for death, $0.72 ; 95 \%$ CI, 0.54-0.95). The absolute difference in survival was $13.2 \%$ (95\% CI, 2.2\%-24.1\%). The Figure demonstrates the increasing survival benefit of the ERV group after 1 month $(P=.04)$. After exclusion of 8 patients with aortic dissection, tamponade, or severe MR, the 1-year survival rate was $47.6 \%(n=147)$ for the ERV and $33.6 \%$ $(\mathrm{n}=146)$ for the IMS groups, a $14.1 \%$ absolute difference (95\% CI 2.9\%$25.2 \% ; P<.02)$.

Three ERV patients and 1 IMS patient underwent cardiac transplantation; 2 survived to 1-year postrandomization.

Most patients (64\%) had 3-vessel disease $^{5}$ and the mean (SD) left ventricle ejection fraction was $29 \%(11 \%)(n=46)$. Ninety-seven percent of ERV patients underwent coronary angiography and $87 \%$ underwent revascularization, including 55\% $(\mathrm{n}=84)$ with PTCA and $38 \%(\mathrm{n}=57)$ with CABG surgery. In the ERV group, the median time from randomization to revascularization was 0.9 hours for PTCA and 2.7 hours for CABG surgery.

Delayed revascularization was attempted in 32 IMS patients (21\%) at a median of 103 hours after randomization, and $4 \%$ underwent revascularization at 54 hours or less. ${ }^{5}$ Initial medical stabilization patients who survived the first several days after randomization and were clinically selected to undergo revascularization had a 57\% (21/ 37) 1-year survival rate. Their mean (SD) cardiac index was higher than IMS patients who did not undergo revascularization $(2.02[0.55]$ vs $1.68[0.46]$ $\left.\mathrm{L} \cdot \mathrm{min}^{-1} \cdot \mathrm{m}^{2-1} ; \mathrm{P}<.01\right)$.

Only 1 of 10 prespecified subgroup analyses revealed a significant interaction with treatment (age $<75$ vs $\geq 75$ years; interaction, $P=.03$ ). There was an $18 \%$ absolute difference in survival in fa-
Figure. Kaplan-Meier Survival Curve 1-Year Postrandomization

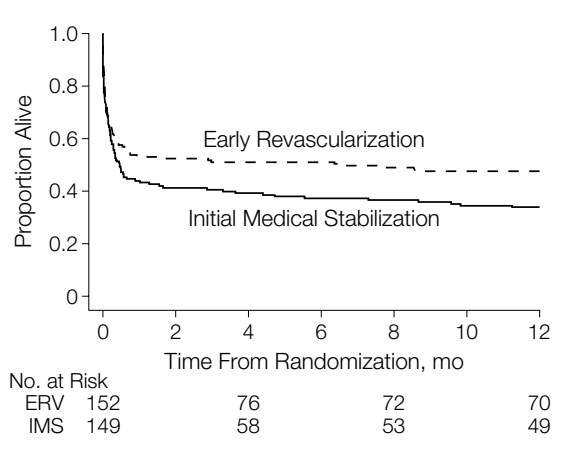

Survival estimates for early revascularization $(n=152)$ and initial medical stabilization $(n=149)$ groups. Logrank test $P=.04$. ERV indicates early revascularization group; IMS, initial medical stabilization group.

vor of ERV patients for those younger than 75 years $(51.6 \%$ for ERV vs $33.3 \%$ for IMS; 95\% CI for the difference, 6.1\%$30.4 \%$ ) and no significant difference in survival between the 2 groups for those 75 years and older (20.8\% for ERV vs $34.4 \%$ for IMS). There was no interaction between treatment effect and presence vs absence of the following variables: male sex, randomization 6 hours or less after AMI, anterior AMI, prior AMI, diabetes mellitus, hypertension, US site, transfer, and thrombolytic contraindication.

Among 1-year survivors ( $\mathrm{n}=90), 83 \%$ were in the NYHA congestive heart failure (CHF) class I or II ( $85 \%$ of the ERV group and $80 \%$ of the IMS group). The overall rehospitalization rate was similar for 69 ERV and 51 IMS patients ( $20 \%$ vs $18 \%$ ); CHF ( $9 \%$ vs $12 \%$ ), angina ( $7 \%$ vs $2 \%$ ), and recurrent AMI (0\%) respectively.

\section{COMMENT}

In this randomized trial of patients with AMI complicated by CS, ERV resulted in a 39\% improvement in 1-year survival compared with initial aggressive medical stabilization. The absolute benefit of ERV for CS, 132 lives saved for every thousand patients treated, is greater than ${ }^{10}$ or similar to the absolute benefit of CABG for left main vessel disease at 1 year. ${ }^{11}$ However, the group difference of 9.3 percentage points in favor of ERV 
at 30 days (reported previously as the primary study end point) did not reach statistical significance. ${ }^{5}$ The increasing survival difference over time is in contrast with other therapies for AMI, such as thrombolysis and primary PTCA, for which maximal benefit is manifested at 30 days. ${ }^{12,13}$ The early mortality difference between primary PTCA and thrombolytic agents decreases over time for AMI patients without CS. ${ }^{13,14}$ However, the angiographic substudy of GUSTO I (Global Utilization of Streptokinase and Tissue Plasminogen Activator for Occluded Coronary Arteries I) demonstrated divergence of the survival curves in the first year for those with normal vs abnormal coronary artery blood flow early after experiencing AMI. ${ }^{15}$ Our findings are consistent with results of randomized trials of CABG compared with medical therapy for high-risk patients with severe coronary artery disease, for whom an early hazard of surgery is more than offset only after long periods of follow-up. ${ }^{16,17}$

The higher 1-year survival with ERV was remarkably consistent among subgroups. The notable exception was a differential treatment effect by age. The younger patients ( $<75$ years) derived a large benefit from ERV, in contrast to an apparent lack of benefit for those 75 years or older. However, the experience of the small elderly cohort $(n=56)$ in the trial is in contrast with results of the concurrent nonrandomized SHOCK Registry, which showed an apparent survival benefit for those 75 years or older who were clinically selected to undergo ERV. ${ }^{18,19}$ These data suggest that a routine strategy of ERV may not be appropriate for the elderly as a group but careful case selection might lead to increased survival in certain patients 75 years or older.

Based on the results of the SHOCK Trial, the American College of Cardiology/American Heart Association recently revised guidelines to recommend ERV for patients younger than 75 years with CS within 36 hours of AMI. ${ }^{20}$

In summary, ERV improves 1-year survival for patients with AMI complicated by CS. We recommend rapid transfer of patients with AMI and CS, particularly those younger than 75 years, to tertiary care hospitals with capabilities to perform urgent coronary angiography and revascularization.

Author Contributions: Drs Hochman and Sandborn participated in the study concept and design, acquisition of data, analysis and interpretation of data, drafting of the manuscript, critical revision of the manuscript for important intellectual content, obtained funding, and provided administrative, technical, or material support and supervision.

Dr Sleeper participated in the study concept and design, analysis and interpretation of data, drafting of the manuscript, critical revision of the manuscript for important intellectual content, and provided statistical expertise.

Drs White and Boland participated in the study concept and design, acquisition of data, analysis and interpretation of data, and critical revision of the manuscript for important intellectual content.

Dr Dzavik participated in acquisition of data, analysis and interpretation of data, drafting of the manuscript, and critical revision of the manuscript for important intellectual content.

Dr Wong participated in acquisition of data and critical revision of the manuscript for important intellectual content.

Dr Menon participated in analysis and interpretation of data, drafting of the manuscript, and critical revision of the manuscript for important intellectual content, and provided administrative, technical, or material support. Dr Webb participated in the study concept and design, acquisition of data, analysis and interpretation of data, drafting of the manuscript, and critical revision of the manuscript for important intellectual content.

Dr Steingart participated in acquisition of data and analysis and interpretation of data and provided administrative, technical, or material support and supervision. Dr Picard participated in the study concept and design, acquisition of data, analysis and interpretation of data, drafting of the manuscript, critical revision of the manuscript for important intellectual content, and provided statistical expertise and administrative, technical, or material support.

Dr Menegus participated in the study concept and design, acquisition of data, and critical revision of the manuscript for important intellectual content, and provided administrative, technical, or material support. Dr Buller participated in acquisition of data, analysis and interpretation of data, and critical revision of the manuscript for important intellectual content. Ms Modur participated in the analysis and interpretation of data and drafting of the manuscript and provided statistical expertise.

Dr Forman participated in the acquisition of data and drafting of the manuscript and provided supervision. Dr Desvigne-Nickens participated in the analysis and interpretation of data and critical revision of the manuscript for important intellectual content.

Dr Jacobs participated in the acquisition of data and critical revision of the manuscript for important intellectual content and provided administrative, technical, or material support.

Dr Slater participated in the acquisition of data and critical revision of the manuscript for important intellectual content.

Dr LeJemtel participated in the study concept and design, analysis and interpretation of data, and critical revision of the manuscript for important intellectual content. Funding/Support: Supported by grants RO1HL50020 and RO1-HL49970 from the National Heart, Lung, and Blood Institute.

Acknowledgment: We thank the SHOCK investigators and coordinators for their the hard work and dedication and Richard Fuchs, MD, for his advice and editorial assistance.

\section{REFERENCES}

1. Goldberg RJ, Samad NA, Yarzebski J, Gurwitz J, Bigelow C, Gore JM. Temporal trends in cardiogenic shock complicating acute myocardial infarction. N Eng/ J Med. 1999:340:1162-1168.

2. Becker, RC, Gore JM, Lambrew C, et al. A composite view of cardiac rupture in the United States $\mathrm{Na}$ tional registry of Myocardial Infarction. J Am Coll Cardiol. 1996;27:1321-1326.

3. Gacioch GM, Ellis SG, Lee L, et al. Cardiogenic shock complicating acute myocardial infarction. J Am Coll Cardiol. 1992:19:647-653.

4. Elatchaninoff $H$, Simpfendorfer $C$, Franco I, Raymond RE, Casale PN, Whitlow PL. Early and one year survival rates in acute myocardial infarction complicated by cardiogenic shock. Am Heart J. 1995;130: 459-464.

5. Hochman JS, Sleeper LA, Webb JG, et al. Early revascularization in acute myocardial infarction complicated by cardiogenic shock. NEng/ J Med. 1999;341:625-634. 6. Hochman JS, Sleeper LA, Godfrey E, et al. Should we emergently revascularize occluded coronaries for cardiogenic shock. Am Heart J. 1999;137:313-321.

7. Breslow NE, Day NE. Statistical Methods in Cancer Research, Vol 1: The Analysis of Case-Control Studies. Lyon, France: International Agency for Research on Cancer; 1980. IARC Scientific Pub No. 32

8. SAS System for Windows [computer program]. Version 6.12. Cary, NC: SAS Institute Inc; 1996.

9. S-PLUS for Windows [computer program]. Version 3.3. Seattle, Wash: Statistical Sciences Inc; 1995 10. Varnauskas E and the European Coronary Surgery Study Group. Twelve-year follow-up of survival in the randomized European coronary surgery study. N Engl J Med. 1988;319:332-337.

11. Takaro T, Hultgren HN, Lipton MJ, Detre KM and participants in the study group. The VA Cooperative randomized study of surgery for coronary artery occlusive disease. Circulation. 1976;54(suppl3):III107-III117.

12. Franzosi MG, Santoro E, De Vita C, et al. Tenyear follow-up of the first megatrial testing thrombolytic therapy in patients with acute myocardial infarction. Circulation. 1998;98:2659-2665

13. GUSTO II Angioplasty Substudy Investigators. An international randomized trial of 138 patients comparing primary coronary angioplasty versus tissue plas minogen activator for acute myocardial infarction. N Engl J Med 1997:336:1621-1628.

14. Michels KB, Yusuf S. Does PTCA in acute myocardial infarction affect mortality and reinfarction rates? Circulation. 1995:91:476-485.

15. The GUSTO Angiographic Investigators. The effects of tissue plasminogen activator, streptokinase, or both on coronary-artery patency, ventricular function, and survival after acute myocardial infarction. N Engl J Med. 1993;329:1615-1622.

16. Alderman EL, Fisher LD, Litwin $P$, et al. Results of coronary artery surgery in patients with poor left ventricular function (CASS). Circulation. 1983;68:785-795. 17. Yusuf $S$, Zucker D, Peduzzi $P$, et al. Effect of coronary artery bypass graft surgery on survival. Lancet. 1994;344:563-570.

18. Hochman JS, Buller CE, Sleeper LA, et al. Cardiogenic shock complicating acute myocardial infarction etiologies, management and outcome; overall find ings of the SHOCK Trial Registry. J Am Coll Cardiol 2000;36:1063-1070.

19. Dzavik V, Sleeper L, Hosat S, Cocke T, LeJemtel $T$, Hochman JS. Effect of age on treatment and outcome of patients in cardiogenic shock [abstract]. Eur Heart J Suppl. 1998;19:28.

20. Ryan TJ, Antman EM, Brooks NH, et al. 1999 Update: ACC/AHA Guidelines for the Management of Patients With Acute Myocardial Infarction: Executive Summary and Recommendations: a Report of the American College of Cardiology/American Heart Association Task Force on Practice Guidelines. Circula tion. 1999;100:1016-1030. 